\title{
MDP Bone Scintigraphy in Diagnosis of Polyostotic Fibrous Dysplasia- A Case Report on McCune- Albright Syndrome
}

\author{
Farida Yasmin, Jasmine Ara Haque, Hosne Ara Rahman, Md. Abu Bakar Siddique, Samira Sharmin, \\ Jesmine Ferdous and Monir Uddin \\ Institute of Nuclear Medicine and Allied Sciences, Sir Salimullah Medical College Campus, Mitford, Dhaka
}

Correspondence Address: Dr. Farida Yasmin, Medical Officer, Institute of Nuclear Medicine and Allied Sciences, Sir Salimullah Medical College Campus, Mitford, Dhaka, E-mail: farida.sb.38@gmail.com

\begin{abstract}
McCune-Albright syndrome (MAS) is an extremely rare disorder that classically affects the bones, skin and endocrine system. Classical features are fibrous dysplasia of bone, skin pigmentation and dysfunction of certain endocrine glands. Diagnosis of MAS is usually established on clinical grounds. Different imaging modalities help to confirm the fibrous dysplasia, among those radio iso-tope bone scan is an excellent tool for early diagnosis and evaluation of bony extension.
\end{abstract}

Key words: McCune-Albright Syndrome, Fibrous Dysplasia, Cafe-au-lait pigmentation, Precocious puberty.

\section{INTRODUCTION}

McCune-Albright Syndrome (MAS) is a noninherited disorder with reported prevalence between 1 in 100,000 to 1 in 1,000,000 and has been observed more commonly in females (1). It is characte-rized by the clinical triad of fibrous dysplasia of bone, patches of abnormal skin pigmentation like areas of light-brown skin (cafe-au-lait spots) with jagged borders and autonomous endocrine dys-function. Fibrous dysplasia is a distinctive feature of MAS. Endocrinopathies may include hyper-gonadism, hyperprolactemia, hyperthyroidism, excess growth hormone, Cushing syndrome etc. Gonadal hyper function is considered to be the most common endocrine dysfunction in females, which manifests by precocious puberty. The diagnosis is considered confirmed when at least two of the cardinal features are present (2).

\section{CASE REPORT}

A 14 year old young girl having history of multiple fractures with bony pain was referred to INMAS, Mitford for performing bone scan. According to the clinical history, the first fracture was noticed at the age of three years in the left upper arm which was healed by malunion. Subsequently, she developed other multiple fractures throughout her childhood involving left femur and pelvis. She had undergone surgery for fracture of left femur and had fixation done with plate $\&$ screw. Her menarche was at the age of 9 years. Her birth history was uneventful with normal developmental milestones.

On physical examination, there were several bony deformities in left upper and lower extremities and the patient was unable to walk. She had also noted hyper pigmented spots with irregular mar-gins in the lower back on left side \& left axilla.

$\mathrm{X}$-ray of upper extremity showed multiple lucent areas in the shaft of both humerus with fracture in left humerus. X-ray of pelvis showed deformed pelvis with multiple healed \& unhealed fractures in the neck of both femur. Ultrasonography report revealed hugely enlarged left ovary with hemorr-hagic cysts and cystadenoma in right tubo ovarian region. Biochemical parameters showed high FT4 with low TSH level (hyperthyroid state), low blood phosphate and normal serum calcium and parathormone level.

Although multiple fractures were previously diagnosed in this case by X-ray, but the patient was 
referred to our institute for further skeletal evaluation by bone scan. Bone scan was done with Tc -99m MDP. Scan findings show increased inhomogeneous tracer concentration in all long bones of the body and in maxillo-facial bones. Findings are consistent with polyostotic variety (involves multiple bones) of fibrous dysplasia which was confirmed by biopsy later.

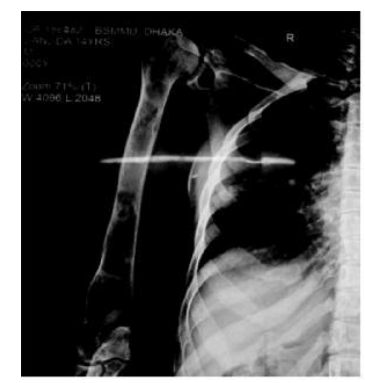

Figure:1(a)

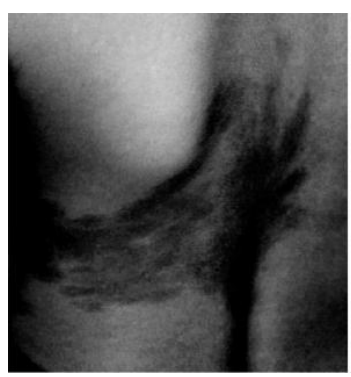

Figure: 1(c)

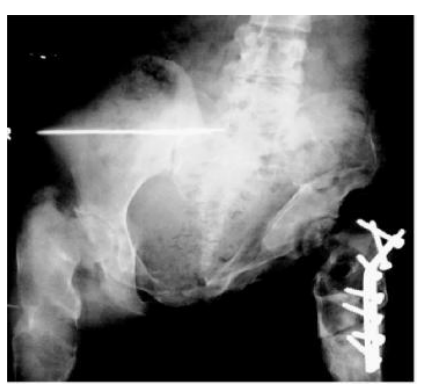

Figure:1(b) 11(b)

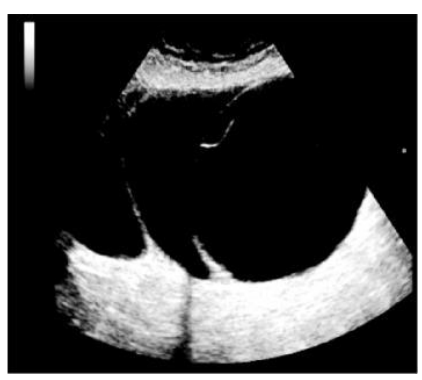

Figure: 1(d)

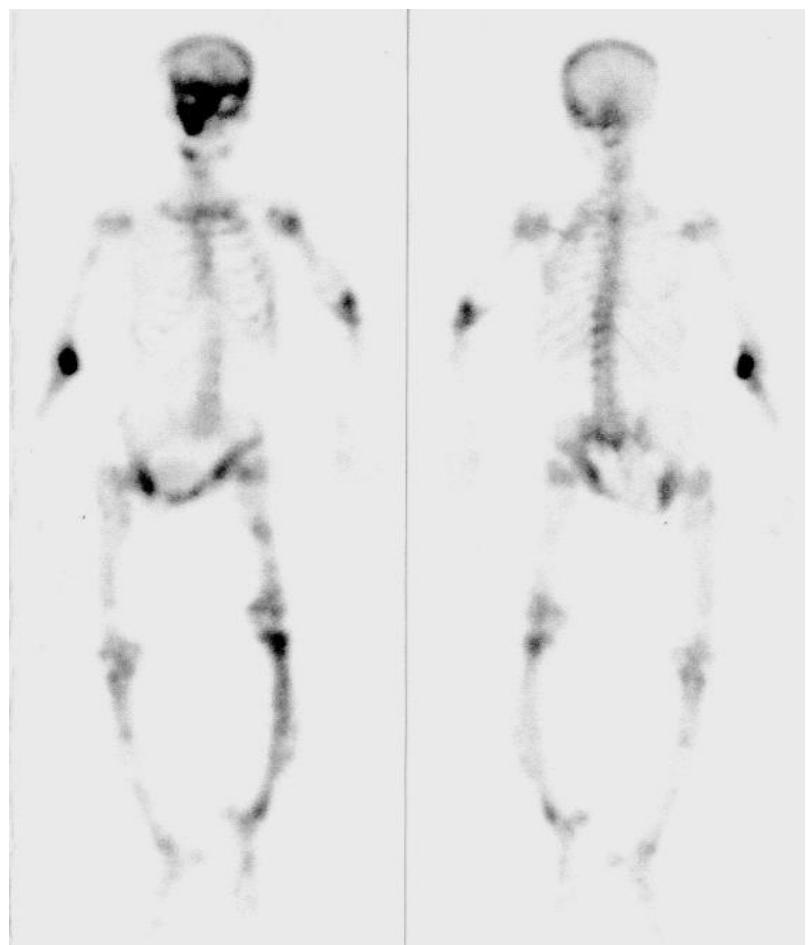

Figure: 2
Figure 1 (a): $\mathrm{X}$ ray shows multiple lytic lesions in shaft of the humerus.

(b): X-ray shows deformed pelvis with multiple healed and unhealed fractures.

(c): Cafe-au-lait pigmentation in back.

(d): Ultrasound imaging shows cystadenoma in right tubo-ovarian region.

Figure 2: Bone scan shows inhomogeneous increased tracer uptake in long bones and maxillo-facial bones.

\section{DISCUSSION}

MAS is a rare non-inherited disorder characterized by the clinical triad of fibrous dysplasia of bone, cafe-aulait skin pigmentation and precocious puberty. Regarding pathogenesis, MAS results from activation of post-zygotic, sporadic mutation of the GNAS1 gene (at locus 20q13.1-13.2) of some cell of the body, not all (mosaic pattern), during embryogenesis (3). This causes a persistent activa-tion of the $G$ stimulatoryalpha subunit of the $G$ protein resulting continuous elevation of intracellu-lar cAMP.

Fibrous dysplasia is a distinctive finding in MAS. In fibrous dysplasia bony tissue is replaced by abnormal scar-like (fibrous) connective tissue which weakens the bone, making it abnormally fragile and prone to fracture. It usually involves metaphysis and/or the diaphysis with sparing of the epiphysis. Specific symptoms associated with polyostotic fibrous dysplasia depend upon the specific bones involved. The disease can affect any part of the skeleton, but the long bones of the arms and legs, the bones of the face and skull (craniofacial area), and the ribs are most often affected. Fibrous dysplasia can be demonstrated by plain radiographs as ground glass appearance. But isotope bone scan is the most sensitive tool for early detection, evaluation of bony extension and prediction of functional outcome (4-10).

This patient presented with skin pigmentation, precocious puberty and bony fractures with no definite cause. X-ray showed multiple healed and unhealed fractures but no definite characteristics of fibrous dysplasia was reported. Initially the possible 
differential diagnosis were hyper parathyroid-ism, neurofibromatosis, non-ossifying fibromas, osteofibrous dysplasia etc. Hyper parathyroidism was excluded as the serum parathyroid hormone (PTH) level was within normal limit. Neurofibro-matosis was excluded in this case as the skin pigmentation had jagged irregular border which was not consistent with neuro fibromatosis. In this case bone scan was in more favour of fibrous dyspla-sia which was later confirmed by histopathology. Due to coexistence of all three cardinal features finally the patient was diagnosed as a rare case of McCune Albright Syndrome.

\section{CONCLUSION}

Isotope bone scan can play very helpful role in early diagnosis of fibrous dysplasia.

\section{REFERENCES}

1. Dumitrescu CE, Collins MT. McCune-Albright syndrome. Orphanet J Rare Dis 2008;3:1-12.

2. Rao S, Colaco MP, Desai MP. McCune Albright Syndrome (MCAS): A Case Series. Indian Pe-diatr 2003;40(1):29-35.
3. Diaz A, Danon M, Crawford J. McCune-Albright Syndrome and Disorders Due to Activating Mutations of GNAS1. J Pediatr Endocrinol Metab 2007;20(8):853-80.

4. Collins MT, Kushner H, Reynolds JC, Chebli C, Kelly MH, Gupta A, Brillante B, Leet AI, Riminucci M, Robey PG, Bianco $\mathrm{P}$, Wientroub S, Chen CC. An Instrument to Measure Skeletal Burden and Predict Functional Outcome in Fibrous Dysplasia of Bone. J Bone Miner Res 2005; 20:219-26.

5. Tekin M, Bodurtha JN, Riccardi VM. Café au lait spots: The Pediatrician's Perspective. Pediatr Rev 2001;22:82-90.

6. Hashemipour S, Larijani B, Adibi H, Sedaghat M, Pajouhi M, Bastan-Hagh MH, Soltani A, Javadi E, Shafaei AR, BaradarJalili R, Hossein-Nezhad A. The Status of Biochemical Parameters in Varying Degrees of Vitamin D Deficiency. Journal of Bone and Mineral Metabolism 2006;24:213-18.

7. Giusti A, Barone A, Razzano M, Pizzonia M, Oliveri M, Palummeri E, Pioli G. High Prevalence of Secondary Hyperparathyroidism Due to Hypovitaminosis D in Hospitalized Elderly With and Without Hip Fracture. Journal of Endocrinological Investigation 2006;29:809-13.

9. Ruggieri P, Sim FH, Bond JR, Unni KK. Malignancies in Fibrous Dysplasia. Cancer 1994; 73:1411-24.

10. Weinstein LS, Shenker A, Gejman PV, Merino MJ, Friedman E, Spiegel AM. Activating Mutations of the Stimulatory G Protein in the McCuneAlbright Syndrome. N Engl J Med 1991;325(24):1688-95. 